\title{
A MISTURA DE CORES DA LITERATURA HÍBRIDA DE LÚCIA HIRATSUKA ${ }^{12}$ \\ THE MIXED COLORS OF THE HYBRID LITERATURE OF LUCIA HIRATSUKA
}

\author{
Janete da Silva Oliveira ${ }^{3}$
}

Resumo: A literatura infantil, como a literatura adulta, parece privilegiar a narrativa escrita. No entanto, a literatura para crianças (principalmente) e jovens, pelas características do seu público, permite mais liberdade no que diz respeito às formas de expressar essa narrativa, como a intensificação do uso de cores e imagens. No presente artigo pretendemos apresentar brevemente a obra da ilustradora, tradutora e escritora de ascendência japonesa, Lúcia Hiratsuka. Objetivamos indicar na obra da autora, que a referência cruzada da cultura japonesa (com uma estética muito particular incorporada, o mono no aware) e a vida interiorana de São Paulo influenciou bastante na criação de uma obra hibridizada, com uma riqueza de cores, afetividade e criatividade que em muito tem contribuído na qualidade da literatura brasileira para crianças e jovens. Para isso, utilizamos uma bibliografia pertinente à estética japonesa, literatura infantil e subjetividade e análise de conteúdo de algumas obras selecionadas da ilustradora. Através dessa metodologia, acreditamos poder apontar a literatura feita por Hiratsuka como ímpar, pois une de forma esteticamente estimulante, criativa e única as cores orientais numa narrativa brasileira e bastante carregada de memória afetiva.

Palavras-chave: Imagem, Japão, literatura infantil, Lúcia Hiratsuka, Mono no aware

Abstract: Children's literature, like the adult one, seems to privilege written narrative. However, literature for the young people and children (especially), due to the characteristics of its audience, allows more freedom regarding the ways of expressing this narrative, such as the intensification of the use of colors and images. In this article we intend to briefly present the work of illustrator,

1 Artigo submetido em 29/10/2019 e aceito em 10/12/2019.

2 Este artigo segue o sistema Hepburn para a transliteração do japonês, os antropônimos seguiram a ordem nome e sobrenomee os topônimos aparecem sem os sufixos japoneses habituais.

3 Professora assistente da Universidade do Estado do Rio de Janeiro (UERJ), Rio de Janeito, Brasil; Doutora pela Pontifícia Universidade Católica do Rio de Janeiro; e-mail: janete.oliveira@gmail.com, (ORCID iD: http://orcid.org/0000-0001-8617-3129). 
translator and writer with Japanese ancestry, Lúcia Hiratsuka. Our aim here is to indicate that the author's work is quite influenced by the cross-reference of Japanese culture (with a very particular aesthetic incorporated, the mono no aware) and the country life of São Paulo, resulting in the creation of a hybridized work with richness of color, affection. and creativity that has greatly contributed to the quality of Brazilian literature for children and young people. For this, we used a relevant bibliography of Japanese aesthetics, children's literature and subjectivity and analysis of the contents of some the illustrator's selected works. Through this methodology, we believe we're able to point to the literature made by Hiratsuka as unpaired, since it unites aesthetically stimulating, creative and unique oriental colors in a Brazilian narrative with a lot of affective memory.

Keywords: Image, Japan, children's literature, Lucia Hiratsuka, Mono no aware

\section{Introdução}

Quando se fala em Literatura, mesmo a infantil, o que vem à mente ocidental, comumente, é a palavra, a narrativa escrita como "O patinho feio", "João e Maria", "Chapeuzinho Vermelho", entre outros, uma história que se materializa para as crianças através de ilustrações. Sobre essa noção do ocidente preferir a escrita, gostaríamos de citar aqui uma contribuição de Linda Hutcheon, professora do Departamento de Inglês e Literatura Comparada da Universidade de Toronto, sobre a problematização da adaptação feita em seu livro "Uma teoria da adaptação". Segundo Hutcheon, amparada na análise do pesquisador e professor de cinema na Universidade de Nova Iorque Robert Stam, a ideia de que a literatura sempre será superior sobre qualquer adaptação, além de ser uma arte mais antiga, envolveria também uma iconofobia (desconfiança do visual) e logofilia (a palavra em primeiro plano) (HUTCHEON, 2013, p. 24). Pensamento que toma a cultura ocidental como padrão. No caso do Japão, esses dois elementos parecem não ter a mesma influência, pelo contrário. Como discutiremos mais à frente, a relação entre imagem e escrita no Japão é algo fundamental para o desenvolvimento da língua e seu desdobramento em narrativas literárias. A despeito das considerações consumistas e financeiras envolvidas, o Japão tem uma tradição milenar de associação entre palavra e imagem já que a própria escrita é ideográfica. São indissociáveis.

Por esse motivo, neste artigo, pretendemos, de certa forma, inverter esse processo evocando uma autora brasileira de ascendência japonesa, cujo caminho para criação de histórias infantis começou com um desenvolvimento inverso, mas ao mesmo tempo tradicional, através de um processo de contação de histórias, falamos da escritora, tradutora e ilustradora Lúcia Hiratsuka.

Nascida em 1960, a autora conta em sua página na internet que, na infância, ao ver a avó rabiscar um peixinho no chão do quintal do sítio Asahi na cidade de Duartina (interior de SP), ela gostou tanto que tentou copiar o desenho e nunca mais parou de desenhar. "De lá para cá foram muitos peixes. Além do quintal, também as paredes das tulhas e o terreiro onde meu pai espalhava café enchiam-se 
de garatujas" ${ }^{4}$. Ela achava mais divertido, para desenhar, usar o carvão retirado do fogão a lenha e lembra-se que, nesses desenhos, tinha sempre uma intenção narrativa, de contar alguma história.

A leitura veio depois, através do avô e dos livros que havia em casa, em sua maioria japoneses. Nessa época também conheceu o ehon, do qual falaremos mais adiante, mas que influenciou também o estilo e a opção da escritora pela ilustração, de contar histórias através da imagem. À época, escolheu seguir esse caminho, sem sequer saber que existia essa profissão. Antes de completar 16 anos, ela parte para São Paulo, saindo pela primeira vez do sítio Asahi (que significa "sol da manhã") onde nasceu e criou-se e, como ela mesma diz "o fim e o começo do mundo". Hiratsuka cursou Artes Plásticas na Faculdade de Belas Artes de São Paulo e lá teve o primeiro contato com a aprendizagem das técnicas artísticas, mas a oportunidade de ir para o campo da ilustração só veio após a formatura. A escritora participou de alguns Salões de Pintura e conquistou alguns prêmios, mas somente o desenho descolado de uma narrativa, não parecia satisfazer, Hiratsuka gostava de narrativas, como ela mesma diz: "do objeto livro, das cenas em sequência, do universo que se abre a partir desse espaço" 5 .

No ano de 1988, Lúcia Hiratsuka recebe uma bolsa para a Universidade de Educação de Fukuoka no Japão e cujo tema de pesquisa foi exatamente o ehon, o livro ilustrado, publicação com a qual teve contato na infância e teve uma influência considerável na carreira da autora. Nessa universidade, Hiratsuka fez exposição de desenhos com as cenas com as quais cresceu: cenas de feira, festa junina, personagens do folclore e paisagens brasileiras. Os desenhos obtiveram bastante sucesso e, na volta ao Brasil, após um ano de estadia no Japão, a escritora e ilustradora começou a recontar, ilustrar e traduzir alguns contos e lendas japonesas ouvidos na infância. Para isso, passou a estudar a técnica do sumie e inspirou-se nas composições japonesas. Contudo, não só as lendas, mas junto a essas narrativas que construíram a história da infância de Hiratsuka, foram adicionadas também as lembranças do cotidiano bem brasileiro no sítio Asahi, seu furusato ${ }^{6}$, conforme ela mesma descreve.

O quintal onde brinquei e tive os meus primeiros bichos, tanto verdadeiros, quanto imaginários, ficou na memória como furusato. Aprendi com minha avó que furusato é onde a gente nasce, mas também é o lugar aonde vamos, em pensamento, quando estamos tristes ou felizes. Hoje tento recriá-lo, com desenhos e palavras.

\footnotetext{
4 Disponível em < http://www.luciahiratsuka.com.br/index.html>. Acesso em agosto de 2019.

5 Idem.

6 Furusato em japonês quer dizer "terra natal".
} 
A partir dessa pequena biografia podemos depreender o quão importante foi a infância nesse ambiente "natural" na formação primeiramente de ilustradora, depois tradutora, mas sempre escritora. As histórias japonesas com as quais a autora teve o primeiro contato, as mukashi banashi (histórias antigas) ou nas histórias cômicas de quatro quadros chamadas de yonkoma (quadrinhos com histórias completas em 4 tiras), como ela cita e mostra na videobiografia elaborada pela Global Editora ${ }^{7}$, ou mesmo no ehon japonês, inspiram obras que se estruturam primeiramente pela imagem ou por uma memória visual e afetiva. Embora a escritora tenha nascido no Brasil, a herança estética japonesa faz-se presente em seu trabalho até porque "ler" em japonês, como ela e a família faziam na infância, é também pensar por imagens, uma caraterística importante da língua japonesa.

\section{Imagem e linguagem}

As questões da língua japonesa surgem, mesmo que marginalmente, segundo a professora Tae Suzuki, a partir do contato com textos budistas (trazidos da China) e pela prática poética, exigência para que a classe aristocrática japonesa do período Heian (794-1185) pudesse expressar seus sentimentos e percepções da natureza em poesia na forma escrita (SUZUKI, 2012, p. 14), em consonância com a análise feita por Haruo Shirane que apresentaremos posteriormente. Logo, foi-se buscar na China, o país conhecido mais avançado para a época, os ideogramas utilizados por aquela nação e esses foram adaptados foneticamente à língua já existente no Japão. A princípio, somente os homens (nobres da corte) ou monges aprendiam os kanji (ideograma chinês). No entanto, a partir desses kanji surgiram dois silabários que ampliaram em muito as possibilidades narrativas da língua japonesa. $\mathrm{O}$ talvez mais importante, em termos literários, tenha sido o hiragana. Isto porque esse silabário deriva de uma suavização (são traços mais planos e arredondados do que o outro que citaremos mais adiante) de alguns ideogramas e foram idealizados por mulheres da corte para escrever seus poemas e, posteriormente, seus romances. O exemplo talvez mais conhecido seria o da dama de companhia da consorte imperial Teishi, esposa principal do Imperador Ichijô (980-1011), Sei Shônagon. É autora de "O livro do travesseiro" (Makura no Sôshi) ${ }^{8}$, cuja história inspirou o filme franco-britânico dirigido por Peter Greenaway em 1996, "O livro de cabeceira". O livro foi finalizado por volta do ano de 1002 e Shônagon descreve, nesse seu escrito, a vida na corte como um diário e, um detalhe interessante que se aproxima das narrativas de Hiratsuka e seu sítio, é o fato de haver trechos dedicados à descrição de insetos entre outros elementos da natureza, bem como do cotidiano da vida palaciana.

7 Disponível em <https://www.youtube.com/watch?v=pVZNvtV35Zw>. Acesso em 01 de agosto de 2019.

8 HASHIMOTO, Madalena Cordaro, São Paulo: Editora 34, 2013. Traduzido por Geny Wakisaka, Junko Ota, Madalena Hashimoto Cordaro, Lica Hashimoto e Luiza Nana Yoshida. 
Um outro exemplo, de aplicação literária do silabário hiragana e também de uma presença feminina na literatura nipônica, agora no gênero romance, é o épico "Narrativas de Genji" (Genji Monogatari, sem publicação no Brasil), escrito por Murasaki Shikibu em 1010, e considerado o romance mais antigo do mundo e a mais importante obra da literatura japonesa. E, observando fotos dos originais de ambas as obras, apesar de simplificações do kanji, a escrita em hiragana também apresenta simetria, conexões e uma estética que busca uma beleza caligráfica que nada tem a dever aos ideogramas chineses.

O outro silabário que faz parte da língua japonesa é chamado de katakana e tem linhas mais retas e parece mais "quadrado" comparado às linhas mais suaves e arredondadas do hiragana. É um sistema também derivado da estética/forma dos ideogramas chineses, no entanto, foi desenvolvida pelos monges budistas para anotações em documentos e sutras budistas (originalmente em língua chinesa) e, a partir do Período Meiji, passou a ser usada para nomes estrangeiros, onomatopeias e, mais contemporaneamente, para ênfase narrativa ou fonética. Há que se notar que para as narrativas, visualmente, o katakana desempenha um papel importante, pois sons "duros", como os ouvidos ao bater, tocar ou quebrar, são expressos nesse silabário, principalmente as sílabas com $\mathrm{K}$ ou $\mathrm{G}$ (sonorização do K). Um exemplo dessa relação do som com o silabário, natureza e seus sons, pode ser visto nas onomatopeias que existem em cerca de três a quatro mil na língua japonesa. As onomatopeias, na língua japonesa, tem como principal objetivo dar variedade à língua e tornar mais clara e objetiva a comunicação. E, por transmitirem de forma fácil e rápida sentimentos, sons e imagens, são muito utilizadas em livros infantis japoneses. Tanto que uma pessoa que usa muitas dessas expressões na oralidade é considerada muito "infantil". Exemplos:

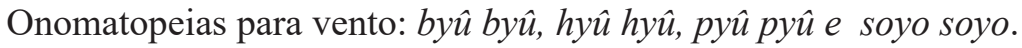

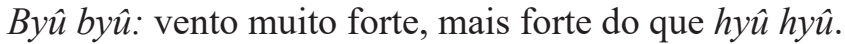

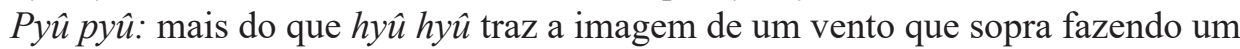
grande barulho.

Soyo soyo $=$ um vento tépido (morno), como na primavera, gentil, um vento que traz um sentimento bom.

Podemos perceber que, aparentemente, toda a língua japonesa remete a um imaginário visual que pressupõe uma imagem estruturadora de narrativa. E, quando falamos desse imaginário visual, de estética japonesa, há que se abrir um grande parêntese, pois desde os seus primórdios, que muitos analistas colocam basicamente como o período Heian, temos mais uma estética do que se "sente ser", mais do que de fato "ser". Pensamos que, para começar a entender esse significado, faz-se necessário construir um modelo de duas camadas sobrepostas a formar uma unidade visual. No caso da literatura de Lúcia Hiratsuka, uma dessas camadas seria a narratividade nipônica 
que, por peculiaridade da língua, já é visual, e a outra seria a leitura afetiva, mais pessoal e visual, a parte que cresceu influenciada pelos cheiros e sentidos no sítio brasileiro. Vejamos uma abordagem desse modelo de "camadas".

Segundo o professor de literatura japonesa e cultura da universidade de Columbia, Haruo Shirane, a cultura poética que emerge em filmes, livros e em várias outras mídias, é uma criação de coletâneas de poesias como o Man'yoshû e Kokinshû, as quais popularizaram a poesia sazonal como um culto e costume da corte para expressar sentimentos. No entanto, representa-se uma natureza restrita aos jardins palacianos que nada tinha a ver com a natureza selvagem que se apresentava aos camponeses. Ele diz que "A sazonalização da natureza no 'waka' foi em grande parte uma construção cultural. O cervo existe o ano todo no Japão, mas na poesia clássica, tornou-se um tema de outono" (SHIRANE, 2012, p. 52). Ou seja, houve uma "escolha" intencional por critérios estéticos arbitrados pela corte do que seria símbolo de qual estação. Shirane continua:

\begin{abstract}
Não há fogo, terremoto, fome, inundações ou secas. Em vez disso, o mundo do Kokinshû é um universo amplamente harmonioso cujas naturezas - na forma de animais, insetos, flores, árvores e condições atmosféricas cuidadosamente selecionados - funcionam como uma expressão elegante e muitas vezes altamente diferenciada do pensamento e da emoção humanas". (p. 45)

A chuva de verão (samidare) é o tema de atmosfera mais proeminente do verão no Kokinshû, comparável à neblina na primavera e à neve no inverno. As longas e opressivas chuvas do Quinto Mês (estação das monções) tornaram-se, pela primeira vez, um tópico importante no período Heian, quando se associaram a pensamentos melancólicos." (p. 39).
\end{abstract}

Shirane menciona também uma associação vocabular entre "samidare" (literalmente os ideogramas significam, chuva do quinto mês) e "midare" (confuso) conectando os dois sentidos: a chuva de verão e depressão/confusão mental dos sentimentos. $\mathrm{O}$ autor acrescenta que, no livro de verão do Kokinsh $\hat{u}$, a imagem do pássaro hototogisu (aparece também no Man'yoshû e seu canto anuncia o florescer da tachibana), mencionado por Sei Shônagon em seus diários como um dos seus pássaros preferidos, a flor chamada de tachibana (flor do verão é a flor da tangerina japonesa, azeda) e samidare, todos esses elementos associados criam "uma paisagem emocionalmente texturizada associada a amor, memória e depressão" (p. 39). Essa estética se materializou nas obras da época, como mencionamos anteriormente o exemplo de Genji Monogatari, cuja análise particularmente interessou o acadêmico japonês Motoori Norinaga (1730-1801) que chegou a um sentimento frente a essas expressões, o mono no aware. Difícil enquadrar como um conceito de "beleza", por idiossincrasias da estética da palavra "beleza" que só passou a existir no Japão, da 
maneira como a concebemos no ocidente, pode-se dizer, a partir do contato com esse último. Ou seja, a estética de beleza para os japoneses não está no objeto em si, mas sim no sentimento despertado, principalmente pelo ambiente natural, como o descrito por Haruo Shirane,

Sobre mono no aware, temos também o trabalho do filósofo da UFMG, Diogo Porto, que fala de uma poesia espontânea inspirada pelo mesmo, enfatizando o sentido afetivo dessa estética inspirada por um sentimento de efemeridade representada pelos fenômenos da natureza. "A interpretação que propomos é, antes, mais direta e simples: para Norinaga, nosso primeiro e mais espontâneo contato com o mundo é afetivo, e responder adequadamente a essa comoção é uma forma profunda de conhecer o mundo, conhecimento esse que se expressa por meio de cantos e poemas" (PORTO, 2016, p. 69). Assim como a professora de literatura japonesa da USP, Neide Hissae Nagae, debruça-se sobre a mesma estética falando do conceito de okashi:

okashi é o conceito representado pela obra Livro de cabeceira, concluído por volta de 1002 pela dama da corte Sei Shōnagon, privilegiando o momento do prazer e do deleite no registro de suas observações diretas e perspicazes do que era interessante na vida palaciana enquanto servia à imperatriz Teishi, primeira esposa do imperador Ichijō (NAGAE, 2013, p. 123).

Consegue-se resgatar, dessa maneira, o mono no aware como uma poesia, uma narrativa que brota de um sentimento despertado pela relação de afetividade com determinado objeto, que não é universal, mas particularmente inspiradora para determinado indivíduo, aquele que "conhece o mono no aware" (PORTO, 2016, p. 66).

\section{Memória afetiva e a literatura infantil de Hiratsuka}

Nessa perspectiva, no campo de uma produção literária infantil, na qual se pensa por imagens, temos as chamadas kamishibai (teatro de papel) e o ehon (livros de desenho). Começando pelas kamishibai, essas são constituídas de desenhos em sequência que, enquanto narrativa de quem manipula os desenhos, é uma forma de arte simples, prioritariamente voltada para crianças. Percebe-se a simbiose entre uma narrativa oral e sua contrapartida imagética. Já o ehon, livro de ilustração citado por Lúcia Hiratsuka em sua página na internet ${ }^{9}$, é um livro que pode ser só composto de imagens ou não, mas segundo a escritora, o importante seria privilegiar o caráter lúdico e o imaginário através de brincadeiras ou poesias. Hiratsuka aponta as origens do ehon no emaki, escrito bastante conhecido no período Muromachi (1336-1573):

9 Disponível em <http://www.luciahiratsuka.com.br/index.html>. Acesso em 01 de agosto de 2019. 
Percorrendo a história, chegaremos ao emaki que associava pinturas e palavras em um rolo. Na era Muromachi (1336 a 1573), os romances em emaki eram bastante apreciados pela população.

Já no início da era Edo (1603 a 1867), começam a surgir os ehons encadernados em formato de livros e tornam-se bastante populares, aproximando-se também das crianças. Antes pintados manualmente, passam a ser impressos em gravuras de madeira, possibilitando assim muitas cópias. Os livros de capa vermelha traziam lendas ou histórias antigas, principalmente para o público infantil. E ehons de capa preta eram mais dirigidos para roteiros de peças de kabuki, fatos históricos, biografias de heróis, etc.

No início da era Taisho (1912 a 1926), surgiram nomes importantes de doowa (literatura para crianças) e dooga (pintura para livros de crianças), que mantém uma estreita relação com os ehons. Atualmente, esse é um mercado amplo, com imensa variedade de obras nacionais e estrangeiras - e um espaço à parte nas livrarias. Apesar de o público-alvo ser formado por crianças, muitos adultos adquirem ehons dos seus autores preferidos para coleção, pois vêm em capa dura com acabamento gráfico precioso. Os pais adquirem esses livros ilustrados para os filhos, desde bebês, com o intuito de entreter, incentivar a imaginação e proporcionar um contato com o objeto livro e despertar a sensibilidade. ${ }^{10}$

Por essa citação, pode-se perceber a importância que sempre se deu, no Japão, ao desenvolvimento de uma literatura infantil e, que influenciou diretamente a autora através do contato com essas narrativas ilustradas em sua infância.

Baseado nesses ehons, um bom livro ilustrado não se sustenta apenas com grandes efeitos de técnica. É preciso um bom desenho, um bom texto e uma boa montagem. Como uma expressão artística, em que o livro é o suporte, deve-se considerar a virada das páginas, a sequência, o fluxo e o ritmo das imagens e como estes se relacionam com as palavras. ${ }^{11}$

Com esse percurso, pretendemos situar a imagem como um pressuposto da narrativa, por si mesma, ou seja, pela via da escrita ideográfica japonesa. Esse pressuposto faz-se necessário para entender o processo de subjetivação da própria Hiratsuka, cujo interesse pela ilustração e construção de narrativas, veio por intermédio da contação de histórias feita pelos parentes japoneses, envolvido em um ambiente natural que se cristalizava em suas ilustrações, iniciadas ainda no sítio, na terra mesmo.

10 Idem.

11 Ibidem. 
A memória funciona como ponto de partida para a inspiração. Além das lendas, que tem um tom de contos populares ou fábulas, os autorais não têm um tom de memória tipo "quando eu era criança". Eu me inspiro em coisas que me encantaram na infância e tento trazer para o agora. Através da memória, para escrever, tento me conectar com a criança que eu fui um dia e ainda está dentro de mim. (HIRATSUKA, 2013a)

Como sua inclinação para desenhar peixes, dito em um vídeo na plataforma YouTube $^{12}$, e no início deste texto, a avó desenhou um peixe no terreno do sítio e, desde então, ela, Lúcia, teria desenvolvido uma atração por desenhar peixes, como podemos observar no seu livro "Chão de Peixes". Aqui podemos pontuar uma diferenciação entre a formação de subjetividades/processo de subjetivação das crianças japonesas e brasileiras. E, embora Hiratsuka seja brasileira, o seu processo de subjetivação mostra-se hibridizado, sendo que está dividido entre o ambiente cultural familiar cercado de referências japonesas do sítio Asahi, o ambiente natural e o social da escola que vem posteriormente. De um lado, a niponicidade imagética era potencializada pelas histórias da família e ilustrações e, de outro, a brasilidade era incutida no ensino do português e no ambiente "caipira" do interior de São Paulo. Segundo John Stephens, em seu livro "Subjectivity in Asian Children's Literature and Film", logo na introdução, ele indica que no momento da leitura, a criança usa os livros para ativar a divisão entre as influências naturais e culturais, o consciente e o inconsciente (2013, p. 3), no entanto, o autor também alerta a respeito dos Estudos Asiáticos, particularmente o Japão, terem sofrido com uma profunda "etnocentria", citando o autor Naoki Sakai. Sakai argumenta que a aceitação de "aproximações teóricas" através das culturas tomou lugar sem se fazer as devidas interrogações das implicações políticas de formulações epistêmicas e sociais que são profundamente etnocêntricas e eurocêntricas (apud STEPHENS, 2013 , p. 5$)^{13}$.

Um conceito central em que a pressão para se conformar distingue a subjetividade japonesa e ocidental é um paradoxo da atuação em relação aos costumes, expectativas e normas éticas de uma comunidade, e o papel da empatia nessa relação. As normas da comunidade não são seguidas simplesmente porque são

12 Disponível em <https://www.youtube.com/watch?v=YDLF8qy48ac>. Acesso em 19 de agosto de 2019.

13 A core concept in which the pressure to conform distinguishes Japanese and Western subjectivities is a paradox of agency in relation to a community's customs, expectations and ethical norms, and the role of empathy in this relation. The community's norms are not followed simply because they are dictated by an authority external to the subject but because the subject affirms them. Put another way, the subject consciously affirms and chooses a course of action mandated by the culture's structures of ethics and empathy. (tradução nossa) 
ditadas por uma autoridade externa ao assunto, mas porque o sujeito as afirma. Em outras palavras, o sujeito conscientemente afirma e escolhe um curso de ação ordenado pelas estruturas de ética e empatia da cultura. (STEPHENS, 2013, p. 175)

A educadora e professora na Universidade da California-Santa Cruz, Barbara Rogoff, em sua argumentação, fala da influência no desenvolvimento humano, a partir das práticas culturais e circunstâncias da comunidade (apud STEPHENS, 2013, 60).

Ela conclui que as crianças são em grande parte moldadas por como a comunidade vê a "infância" (p. 23), embora também reconheça os efeitos de rituais e crenças tradicionais. A segregação de crianças de atividades adultas indica que a comunidade vê a infância como preparação para a vida e isso é contrastado com a atitude de ver as crianças como participantes da comunidade, de modo que o desenvolvimento infantil é grandemente influenciado pela expectativa de uma comunidade para as crianças, e a expectativa é parcialmente formada pela prática social cotidiana (STEPHENS, 2013 , p. 60). ${ }^{14}$

E ao que Rogoff chama de identity-with (identidade-com) e difference-from (diferença-de), no caso das histórias infantis japonesas temos, na maioria das vezes, a identity-with quando as crianças participam desde cedo das atividades da comunidade juntamente com os adultos. Podemos perceber isso em obras de Hiratsuka como "Ladrão de ovos" (2011), quando as crianças participam ativamente nas atividades do sítio e identificam-se com aquela paisagem natural, realizando as tarefas cotidianas. Assim como existe a "Coleção Histórias do Quintal" (da qual a obra supracitada faz parte), e a autora resgata histórias da sua memória afetiva da infância no sítio Asahi. Informação confirmada pela resenha que consta na página da Pluricom - Comunicação integrada das Edições SM, pela qual foi publicada uma parte dessa coleção,

As lembranças de Lúcia Hiratsuka servem de inspiração para essas histórias, que colocam os leitores em contato, mesmo que indiretamente, com uma leitura de viés memorialista. As narrativas põem em destaque uma outra temporalidade, bem como demonstra a riqueza da memória afetiva e do respeito à própria história,

14 She concludes that children are largely shaped by how the community views "childhood" (p. 23), although she also acknowledges the effects of rituals and traditional beliefs. The segregation of children from adult activities indicates the the community views childhood as preparation for life, and this is contrasted with the attitude of viewing children as participants in the community. Thus child development is greatly influenced by a community's expectation for children, and expectation is partly formed through everyday social practice. (tradução nossa) 
a coisas aprendidas na infância e ao ambiente de origem - valores muitas vezes deixados de lado no mundo contemporâneo, especialmente nas grandes cidades. ${ }^{15}$

O trabalho da autora reflete essa memória afetiva que podemos aproximar de obras do período Heian japonês, como Sei Shônagon e Murasaki Shikibu, inclusive pelo uso de técnicas de caligrafia japonesa como o sumie ${ }^{16}$, na qual se utiliza, como mistura, água e carvão (sumi) para as pinturas feitas com pincel, base de muitas de suas ilustrações, além de giz de cera, utilizado com frequência pela ilustradora. O resultado é uma trajetória de cores que dá vida à narrativa, a ilustradora mostra o caminho à escritora, como ela mesmo diz sobre a complementaridade das duas linguagens no seu trabalho:

Eu vinha estudando narrativa desde que entrei na área de literatura infantojuvenil, para complementar as ilustrações. A minha intenção, antes de entrar para essa oficina, era contar histórias mais com ilustrações, como o e-hon, o livro de imagens japonês, que estudei no Japão. Queria fazer um livro não só de imagens, mas que tivesse uma frase bem colocada e com desenho. Ou criar uma história em que a ilustração contasse boa parte dela. Mas eu fui me encantando com a possibilidade de criar imagens através da palavra. E outra coisa que me encantou no período da oficina foi a possibilidade de trabalhar com elementos muito simples, do cotidiano. É um contraponto com as lendas japonesas, só acontecem coisas extraordinárias. Aí me despertou para transformar aquela coisa muito simples. (HIRATSUKA, 2013a)

Retomando nosso percurso com a estética japonesa e a literatura infantil, podemos ver que a autora, por estar em contato desde pequena com a estética de contar histórias japonesas, essas de uma longa tradição de uma imagética natural envolta na camada imaginária de uma abstração de natureza que inspire emoções e uma camada da leitura afetiva, a poesia espontânea de quem conhece o mono no

15 Disponível em <http://www.pluricom.com.br/clientes/grupo-sm/noticias/2012/01/lucia-hiratsukalanca-primeiros-titulos-da-colecao-historias-do-quintal-em-que-resgata-sua-propria-infancia-numsitio-no-interior-de-sao-paulo>. Acesso em 28 de julho de 2019.

16 Simplicidade.

Naturalidade.

Simbolização.

Estes são os 3 elementos básicos do sumiê, nas palavras do mestre Masao Okinaka que introduziu e divulgou esta técnica no Brasil. A partir da China, a arte do sumiê chegou ao Japão, no período Muromachi (1392-1572), com os monges zen-bundistas. Posteriormente, a técnica difundiu-se pelo interior do país e ganhou um estilo próprio, incorporando uma elegante simplicidade. O sumiê tradicional utiliza-se apenas do sumi, uma tinta escura a base de fuligem de alguns vegetais. Disponível em <http://www.luciahiratsuka.com.br/index.html> Acesso em 02/08/2019. 
aware como afirma Porto (p. 66).

Quando a gente é criança, a gente se espanta por qualquer coisa, né ? E quando a gente convive com as crianças, percebe que esqueceu que se espantava com um caracolzinho ou outro detalhe. E muito de minhas lembranças vêm de minha avó, das cantigas que ela cantava, das histórias cheias de detalhes. Contou do monge que foi professor dela, que ele a conduzia segurando na mão. Ela contou que, uma vez, estava fazendo limpeza, e chegou uma colega mais velha e disse que o nome dela estava fixado no mural, no corredor. A avó pensou que tinha feito alguma coisa errada. Depois, foi olhar, viu que era o exercício de shodo (caligrafia) que estava fixado no mural. Ela contou com suspense, era uma narradora de histórias nata. Se vivesse em uma outra época, seria escritora. (HIRATSUKA, 2013a)

Em seguida, escolhemos cerca de metade das obras publicadas pela escritora, excluindo as mukashi banashi traduzidas pela autora, pois essas não são de "autoria" dela, mas apresentaremos algumas adaptações de lendas japonesas ou contos influenciados por elas. Tentaremos apontar nas obras os indicadores conceituais, dos quais falamos até aqui.

\section{Breve análise de algumas obras}

Em "Lin e o outro lado do bambuzal" (SM, 2004), temos três elementos que remetem a um imaginário oriental/japonês num ambiente natural: a raposa Lin e sua aprendizagem na arte da transformação (técnica que aparece em muitas mukashi banashi e lendas japonesas); o bambu que é símbolo de resiliência e inclusive é utilizado em arranjos representativos do ano novo; e a menina Yumi e sua casa, vestimentas e ambiente claramente referenciado no Japão. Tudo isso se combina para apresentar uma ideia de amizade e ver além das aparências, sentir a beleza mais do que vê-la. Um elemento essencial do mono no aware.

O livro "Um rio de muitas cores" integra a Coleção Olho Verde (Studio Nobel, 1999), cuja concepção tem a ver com contação de histórias através de imagens, prescindindo de uma narrativa escrita. Um conceito muito similar ao ehon japonês que também se utiliza apenas de imagens para narrar. "Um rio de muitas cores" faz o leitor acompanhar uma história similar à Chapeuzinho Vermelho mas sem lobo, apenas uma jornada florida por paisagens diversas, um tema muito caro à autora e já abordado em livros como Na janela do trem, um pouco em Orie, entre outros.

Seguindo a linha das imagens que inspiram narrativas, o que foi dito pela própria autora em entrevista já reproduzida aqui pela revista MEMAI (HIRATSUKA, 2013a), temos o livro "Chão de Peixes" (Pequena Zahar, 2018) remetendo diretamente à infância da autora, uma vez que ao ver a avó desenhar um peixe na terra do sítio em Duartina, desenvolve uma paixão por peixes, logo o título reflete esse acontecimento. No entanto, 
o livro não conta uma "história" linear para as crianças, mas sim parece fluir a imagem e uma "poesia espontânea" inspirada pelas ilustrações usando a técnica japonesa do sumie, e pela memória afetiva da escritora, algo que é muito similar ao que vemos no "Livro do travesseiro" de Sei Shônagon. O que aponta novamente a presença dos elementos de mono no aware e a poesia espontânea (PORTO, 2016, p. 73) e que pode ser criada a partir do conhecer desse "sentimento".

Ainda com relação à memória afetiva da ilustradora, temos o livro "Orie" (Pequena Zahar, 2014), uma homenagem à avó de Hiratsuka e às lembranças da vida dela no Japão e relatados à neta, o próprio tom de cor escolhido para as páginas do livro remete à questão da terra, muito presente nas obras da ilustradora. Como, por exemplo, na já citada coleção "Histórias do Quintal" da qual fazem parte os livros "Ladrão de ovos", "O ogro e as galinhas", "Terra costurada com água", entre outras. E, segundo a resenha das edições SM, editora pela qual foram publicados os títulos:

As memórias de infância da própria autora são o foco desta nova coleção, lançada por Edições SM. Com temas que abordam a solidariedade, a perseverança, as relações familiares e o meio ambiente, a Coleção Histórias do Quintal reúne narrativas com cheiro de mato e chão de terra batida, gosto de café passado na hora e cacarejos e latidos ao fundo. ${ }^{17}$

Retomando essa coleção com o título "Terra Costurada com Água” (SM, 2014), Lúcia Hiratsuka volta a recorrer à sua memória afetiva da infância no sítio em Duartina para colocar um pouco de poesia numa atividade corriqueira no interior, o brincar com o barro. $\mathrm{O}$ "tecer" de um imaginário do barro com água, de costura de memória e amizade. E, ainda utilizando o elemento "água" como aglutinador dos personagens da história, temos "Histórias guardadas pelo rio" (SM, 2017), o fluir da água e de história que são "pescadas", "estocadas", "vendidas" e largamente compartilhadas nos vilarejos que circundam o rio. Pedro pescava boas histórias quando criança, no entanto, já mais velho, perdera essa capacidade, e buscava uma maneira de voltar a pescar boas histórias. Essa necessidade leva o menino a uma viagem à procura do "mestre" Guido, mas que vai, de fato, conduzi-lo ao verdadeiro caminho para pescar de novo histórias.

O tema da viagem, de novas paisagens, é recorrente na obra da autora, como já citamos aqui em "Um rio de muitas cores", reaparece em "Histórias guardadas pelo rio" e aparece com toques da infância da autora, em "Na janela do trem" (Cortez Editora, 2013b), pois a autora diz na segunda orelha de livro: "As minhas primeiras viagens foram de trem. Junto com minha avó, ia visitar os primos que moravam longe. (...) Até

17 Disponível em <http://www.pluricom.com.br/clientes/grupo-sm/noticias/2012/01/lucia-hiratsukalanca-primeiros-titulos-da-colecao-historias-do-quintal-em-que-resgata-sua-propria-infancia-numsitio-no-interior-de-sao-paulo>. Acesso em 20/08/2019. 
hoje adoro passeio de trem e ver a paisagem pela janela".

Outro tema que a escritora retoma com frequência são as cores, e em "As cores dos pássaros" (Rovelle, 2016) vai buscar numa fábula japonesa, ouvida quando criança, retornar a momentos vividos à época: "o que mais dá prazer é contar esses encantos, brincando com as cores, com as pinceladas e com as palavras. Isso me torna um pouco criança outra vez". Assim como em "Chão de peixes", as imagens vão criando narrativas no desfile de cores, neste livro de pássaros, e no qual a autora inclui também pássaros brasileiros, complementando a história com o "eu" brasileiro da ilustradora.

Esse "eu", que guarda a memória da vida caipira temperado com um "algo" oriental, reaparece no livro "Tantos Cantos" (Editora DCL, 2013c), quando a ilustradora cria uma narrativa a partir das suas lembranças da mãe costurando e da brincadeira com a irmã através dos sons. Isso remete às onomatopeias japonesas, muito comuns em livros infantis do Japão e recuperadas aqui. Bem como podemos fazer uma analogia com o título escolhido por Hiratsuka que inclui a palavra "cantos", cujo significado poderia ter seu uso ligado aos sons das lembranças das histórias formando um canto como que se transforma em narrativa escrita, assim como a poesia japonesa, cuja composição da palavra, um ideograma, possui um símbolo que também significa música, canto $(k a, u t a)$. Então temos uma pitada de poesia japonesa num conto sobre o cotidiano do interior. "Nunca mais esqueci o som da máquina de costura. Também lembro das cantigas recheadas de onomatopeias, que me fizeram perceber a poesia do dia a dia. Tantos cantos me acompanham" (HIRATSUKA, 2013c).

Esse lado de “menina do sítio", embora não de forma autobiográfica, está presente também em "Corrida dos caracois "(Global Editora, 2010), da já citada coleção Histórias de Quintal, obra na qual retoma os personagens Lina e Nico em uma brincadeira no quintal com caracóis, exortando a um imaginário natural povoado de plantas, mato e vida de sítio com a mãe pedindo alface da horta. Uma história que traz para a autora e leitores aquele gosto de brincadeira de infância e os desejos de compartilhar através de livros. Desejo esse de ilustrar e contar histórias pela imagem está retratado em "A visita" (Editora DCL, 2011). Um livro só com ilustrações que levam o leitor a uma viagem de medo e insegurança, mas culminam numa descoberta que harmoniza com a da própria escritora em relação ao seu fascínio pela contação de histórias pelo viés da narrativa imagética.

\section{Considerações finais}

Finalizando essa breve análise de algumas obras da Lúcia Hiratsuka, abordaremos uma mistura das duas Lúcias, a caipira e a herdeira de cultura oriental, a publicação "Festa no céu/Festa no mar" (Editora DCL, 2007) no qual a escritora mescla, de forma delicada e inteligente, as duas culturas através de duas histórias cujo resultado em termos afetivos e narrativos é o mesmo, embora oriundo de culturas diferentes: o motivo do casco da tartaruga ser como é. E fica-nos a narrativa de que, mesmo diferentes, sempre 
encontramos um ponto em comum, maneiras de contar diferentes, mas humanos somos e sentimos o mesmo encantamento ao ouvir histórias.

Como consideração final, tentamos fazer uma classificação das obras da autora para deixar mais clara essa mistura de cores em sua obra, razão da sua riqueza, variedade e importância para uma literatura infantil plural e rica.

\begin{tabular}{|c|c|c|}
\hline Influência "caipira" & Influência oriental & Influências hibridizadas \\
\hline Ladrão de ovos & Histórias tecidas em seda & Chão de peixes \\
\hline Antes da chuva & Orie & As cores dos pássaros \\
\hline O ogro e as galinhas & Os livros de Sayuri & O caminhão \\
\hline A corrida dos caracóis & Issum Boshi & Na janela do trem \\
\hline A venda & Histórias de mukashi & Tantos cantos \\
\hline Guardião da bola & Contos da montanha & Um rio de muitas cores \\
\hline Páscoa no galinheiro & O rouxinol e o imperador & Lin e o outro lado do bambuzal \\
\hline A visita & Momotarō & Terra costurada com água \\
\hline Festa no céu/Festa no mar & O noivo da ratinha & Histórias guardadas pelo rio \\
\hline Muli & & Festa no céu/Festa no mar \\
\hline
\end{tabular}

\section{Referências}

HIRATSUKA, Lúcia. Lúcia Hiratsuka e a "contemplação caipira". [Entrevista concedida a] Marilia Kubota. Revista Memai: letras e artes japonesas. n. 19, 07 de março de 2013a. Disponível em <https://revistamemai.wordpress.com/2013/03/07/19-entrevista-luciahiratsuka-e-a-contemplacao-caipira/>. Acesso em 10/08/2019.

HIRATSUKA, Lúcia. Chão de peixes. Rio de Janeiro: Pequena Zahar, 2018.

HIRATSUKA, Lúcia. Cores dos pássaros, As. Rio de Janeiro: Rovelle, 2015

HIRATSUKA, Lúcia. Corrida dos caracois. São Paulo: Global, 2010.

HIRATSUKA, Lúcia. Festa no céu: Conto popular do Brasil/Festa no mar: Conto popular do Japão. São Paulo: DCL, 2007.

HIRATSUKA, Lúcia. Histórias guardadas pelo rio. São Paulo: Edições SM, 2018.

HIRATSUKA, Lúcia. Histórias tecidas em seda. São Paulo: Cortez Editora, 2010.

HIRATSUKA, Lúcia. Ladrão de ovos. São Paulo: Comboio de Cordas, 2011. 
HIRATSUKA, Lúcia. Lin e o outro lado do bambuzal. São Paulo: Edições SM, 2015.

HIRATSUKA, Lúcia. Na janela do trem. São Paulo: Cortez Editora, 2013b.

HIRATSUKA, Lúcia. Ogro e as galinhas, O. São Paulo: Comboio de Cordas, 2011.

HIRATSUKA, Lúcia. Orie. Rio de Janeiro: Pequena Zahar, 2014.

HIRATSUKA, Lúcia. Rio de muitas cores, Um. São Paulo: Studio Nobel, 1999.

HIRATSUKA, Lúcia. Terra costurada com água. São Paulo: Edições SM, 2014.

HIRATSUKA, Lúcia. Tantos cantos. São Paulo: Editora DCL, 2013c.

HIRATSUKA, Lúcia. Visita, A. São Paulo: DCL, 2011.

HUTCHEON, Linda. Uma teoria da adaptação Florianópolis: Editora da UFSC, 2 ${ }^{\mathrm{a}}$ ed., 2013.

NAGAE, Neide Hissae. Os poemas japoneses tradicionais e as suas peculiaridades - a concretude da beleza numa arte motivada pelo encanto sazonal. In: Do-caminho da arte: do belo do Japão ao Brasil. NAGAE, Neide Hissae; SHIODA Jo Cecilia Kamie; YOSHIURA, Eunice Vaz (Org.). São Paulo: Editora Unesp, 2013. p. 113-130.

PORTO, Diogo da Silva. Mono no Aware e sua relevância filosófica: a melancolia na poética japonesa. In: Freitas,Verlaine; Costa, Rachel; Ferreira, Debora Pazetto. (Org.). O trágico, o sublime e a melancolia. $1^{\mathrm{a}}$ ed.Belo Horizonte: ABRE - Associação Brasileira de Estética, 2016, v. 4, p. 61-79.

SHIRANE, Haruo. Japan and the Culture of the four seasons: nature, literature, and the arts. Nova Yorque: Columbia University Press, 2013.

STEPHENS, John. Subjectivity in Asian Children's Literature and Film: Global Theories and Implications. Abingdon, RU: Routledge, 2012.

SUZUKI, Tae; NINOMIYA, Sônia Regina Longhi; OTA, Junko; MORALES, Leiko Matsubara (orgs). Tópicos Gramaticas da Língua Japonesa. São Paulo: Humanitas: FAPESP, 2012. 